\title{
LEGAL AID REFORM : A VIEW FROM THE VOLUNTARY SECTOR
}

\author{
Les Allamby, Law Centre, Northern Ireland \\ INTRODUCTION
}

The legal aid reform programme and civil justice review have injected a much needed impetus into the debate on access to civil justice for people on low incomes.

Legal aid reform, in particular, has the potential to promote the concepts of planning, co-ordination, quality, added accountability and research into outcomes to the delivery of civil legal services. It will also provide a sharper focus on the financially disadvantaged. A key part of the debate will be shifting attention onto customers rather than providers of services. A cautionary note, nonetheless, needs to be sounded in that other parts of legal aid reform are likely to have a negative impact on the financially disadvantaged. Moreover, paying more attention to social welfare areas of law without addressing financial eligibility for legal aid, access to representation at tribunals and a sufficient budget to sustain civil legal aid services may undermine the aim of targeting legal aid where it is most needed. The recent publication of the draft Access to Justice (NI) Order 2002 still leaves anyone with an interest in how change will operate in practice tantalisingly short of detail.

This article sets out the work of the voluntary sector and examines developments in legal aid in England and Wales, including the idea of a community legal service and its implications for Northern Ireland. It also assesses the impact legal aid reform and specific aspects of the civil justice review will have on the financially disadvantaged.

\section{Voluntary Sector Advice Giving Agencies: The State Of The Sector}

The development of voluntary sector advice from the 1970s onwards was motivated by a desire to take a broader and more strategic approach to providing legal services in disadvantaged communities than that offered within private legal practice. As a result, alongside traditional legal advice and information, voluntary sector advice agencies undertook social security benefit take-up campaigns, social policy work, legal education and information initiatives through poster campaigns, classes and seminars. In addition, a campaigning approach was adopted to ensure that service delivery fed into calls for legislative and policy reform. This work was overtly aimed at improving the social conditions of disadvantaged local communities.

During the 1990s, a more coherent community development strategy was articulated by many advice agencies with an emphasis on the involvement and participation of disadvantaged local people in the delivery of services. Even more recently, a debate has emerged on the role that good quality, 
accessible legal advice and representation can play as part of any strategy to tackle social exclusion and alleviate urban deprivation and rural isolation. ${ }^{1}$ At the same time, however, the additional demands placed on advice agencies have moved them increasingly towards delivering individual advice and representation.

This increase in demand has been caused by a number of factors. Ongoing changes to social welfare law coupled with an inexorable increase in complexity (social security is just one stark example) have made resolving legal problems without the assistance of an independent third party more difficult. In addition, government and public bodies have increasingly sought the views of the voluntary sector when developing and implementing policy changes. This work, largely absorbed within existing resources, left limited time to develop more pro-active and collective legal responses to social problems. Paradoxically, this change makes the voluntary sector more attractive to government as a provider of legal services. Retaining a balance between traditional approaches focussed on the individual and other more strategic and innovative ways of tackling legal and social problems is one of the seminal challenges to the voluntary sector as legal reform evolves.

Mapping the voluntary sector is not easy. There are local advice agencies providing general advice (for example, local Citizens Advice Bureaux) whilst others specialise in a specific area (Foyle Homeless Action and its housing work and the recent development of local advice provision through Victim Support (NI) are good illustrations). Local advice agencies often employ staff in specific areas of law (for example, Limavady Community Development Initiative, East Belfast Independent Advice Centre, and Citizens Advice Bureaux in Craigavon, Newtownards and Dungannon all have money advisers). Regional organisations provide subject specific specialist advice (for example, the Law Centre covers employment, housing, immigration, social security and community care) whilst other regional organisations cater for particular social groups (Help the Aged provide an advice line for older people, Gingerbread, an advice and information service for lone parents). Advice agencies can be part of a bigger organisation with a variety of other functions instead of concentrating solely on advice giving (Age Concern, Northern Ireland Council for Ethnic Minorities, Women's Aid and advice agencies attached to community resource centres in Belfast and Derry are just some examples). Regional organisations also provide services to support local advice giving networks. There are effectively two networks - the Citizens Advice Bureaux, and the independent advice sector.

There are 28 local Citizen Advice Bureaux in Northern Ireland. Many local $\mathrm{CABx}$ also provide advice from outreach centres. Local bureaux provide advice and information across most areas of law through a combination of paid staff and volunteers. Local bureaux are also involved in specific subject based work.

The cornerstone of the Citizens Advice Bureaux's work is its information system providing legal information across a comprehensive range of subjects

1 A recent example is Legal Aid Advice Services. A Pathway out of Social Exclusion, a paper by the Lord Chancellor's Department and Law Centre Federation (November 2001). 
which is available in a CD-ROM as well as paper format. The information is UK wide, supplemented by information provided by the Northern Ireland Association of Citizens Advice Bureaux (NIACAB). This information is updated monthly. Considerable emphasis is placed on the system during the training of voluntary and paid advisers.

Local CABx work is supported regionally by the NIACAB which provides technical and operational support and services (for example, recruitment and selection, social policy, training) as well as its own advice initiatives, specifically an advice line to deal with problems obtaining the national minimum wage and specialist consultancy on social security law and tribunal advocacy.

The Association of Independent Advice Centres (AIAC) represents the interests of independent advice agencies other than local CABx. With 83 members, it provides support to a diverse range of advice agencies ranging from local advice agencies in Omagh, Craigavon, Newry, Derry, Limavady, Belfast and Enniskillen through to regional organisations including Disability Action, Housing Rights Service and Northern Ireland Council for Ethnic Minorities. AIAC provides a range of support services to enhance quality standards and management of member agencies and offers NonVocational Qualification training, information technology, information and policy support.

The Law Centre also operates from a membership base. Unlike its regional counterparts, NIACAB and AIAC, it does not operate as a network to lobby for specific members' interests. Instead, it is a provider of services (an advice line, casework and representation on referral, training, publications and information) to a membership of over 500 organisations encompassing solicitors' firms, probation and social services offices, trade unions, political parties, tenants' associations, occupational welfare organisations as well as voluntary sector advice agencies.

All three organisations share a number of common approaches, particularly the development of information technology to deliver services, the accreditation of training and a commitment to working in partnership with other organisations. The three organisations also make up the Advice Services Alliance, an umbrella body that lobbies for the needs of voluntary sector advice services.

The most recent overview of the sector was produced in an invaluable report commissioned by the Legal Aid Advisory Committee. ${ }^{2}$ In this report, the authors noted that the advice sector had doubled its output in less than ten years, dealing with over 480,000 enquiries in $1999 .{ }^{3}$

A breakdown of the areas of law dealt with showed social security as far and away the largest area of work, covering $54 \%$ of all enquiries, followed by

2 Laura Lundy and Ruth Glenn, Advice Services in Northern Ireland, a report for the Lord Chancellor's Legal Aid Advisory Committee for Northern Ireland (School of Law, Queen's University Belfast, 1999).

3 Good Advice - How does Northern Ireland measure up? (1990) (General Consumer Council for Northern Ireland) estimated the number of enquiries dealt with by the advice sector in 1990 as 240,162 (p11). Advice Services in Northern Ireland assessed that 480,371 enquiries were dealt with in 1999 (p 23). 
housing $9 \%$, consumer $8 \%$, employment $5 \%$, family and children $4 \%$, community care $3 \%$, debt $2 \%$ and immigration $1 \%$. Other areas of law covered the remaining $15 \%$ of enquiries.

Most advice organisations were found to provide representation at social security appeal tribunals, whilst in contrast, relatively few provided similar assistance at industrial tribunals, the small claims court, before the immigration adjudicator and social security commissioners.

Funding for voluntary sector advice services was assessed as amounting to $£ 5.4 \mathrm{~m}$ in 1999 . There were a variety of sources of funding, including the Department for Social Development, European funding (under European Regional Development Funds and peace monies), Health and Social Services Trusts, local district councils, National Lottery Charities Board (now the Community Fund) and charitable trusts. Much of this funding was, however, project based and finite. Lundy and Glenn's research found that $57.3 \%$ of all funding was temporary, which created uncertainties that militated against long-term planning and created a higher level of staff turnover. This particular problem has grown more acute with local advice organisations currently facing a crisis following the reduction in funding from European sources and a contraction in grant aid available through the Community Fund. ${ }^{4}$ The research also conducted a comparison of the cost per enquiry between the advice sector in Northern Ireland and England and Wales. Drawing on figures from the Lord Chancellor's Department White Paper Modernising Justice (1998), the assessed cost of dealing with an individual enquiry was $£ 11.24$ in Northern Ireland and $£ 15.00$ in England and Wales. It is against this backdrop that developments in legal aid in both England and Wales and Northern Ireland must be examined.

\section{Legal Aid Reform in England and Wales}

An initial reading of the draft Access to Justice (NI) Order 2002 provides a strong sense of déjà vu. Reform is, in effect, following a well trodden path. In England and Wales the last ten years have seen government move away from a demand led approach to legal aid towards a more strategic model of delivering services. The key drivers have been financial and managerial. Government has introduced cost controls, quality assurance and a degree of planning for legal services.

The legal aid scheme has effectively been divided in two. Criminal legal aid, provided through a criminal defence service, remains demand led, whilst civil legal aid, re-branded as a community legal service, moved inexorably towards a cash-limited approach. Initially civil legal advice and assistance was undertaken through franchising arrangements with solicitors' practices and the voluntary sector in tandem with the traditional demand led approach. Eventually, a move was made to an almost entirely contractual scheme following implementation of the Access to Justice Act 1999. Contracts provided government, through the (then) Legal Aid Board, with a measure of control previously unavailable to paymasters of legal aid.

4 In May 2002, Belfast City Council provided $£ 93,162$ in order to protect eighteen advice posts in the short term (see AIAC News April 2002). 
This control stems from a variety of different sources. First, contracts for services set out required standards from providers. Working through the Legal Aid Franchise Quality Assurance Standards (LAFQAS), the Legal Aid Board devised a systems led approach to measuring quality by ensuring that specific personnel policies, file review and supervision systems, client care and business planning arrangements were in place. The LAFQAS model underpinned the development of kite marks as a central pillar of quality under the Community Legal Service. These approaches have proved technocratic and failed to develop a dynamic approach to measuring the quality of advice and casework through, for example, peer review, outcome measures and satisfaction surveys. It is interesting to note that the Institute of Advanced Legal Studies research report on the Contracting of Civil, Non Family Advice and Assistance pilot covering 100 firms of solicitors and 43 advice agencies found that voluntary sector advice agencies took significantly longer to deliver services than private practice counterparts but achieved higher levels of quality. ${ }^{5}$

One by-product of these developments was that the Law Society in England and Wales was spurred into action, with specialist panels being introduced in a number of fields including childcare work and mental health review tribunal representation. Moreover, the creation of the Office of Immigration Services Commissioner as the first UK wide independent body to regulate quality control of legal services added another dimension to this debate. Quality standards are no longer a matter solely for the profession and funders of legal aid services.

A second new measure of control was provided through planning and prioritising services. To establish priorities, a Funding Code was devised and regularly updated to reflect a framework of importance set by the Lord Chancellor's Department. Specific priority was to be given to social welfare legal issues (housing, employment, immigration, social security) over other areas. The Funding Code has proved complex and unwieldy. More impact on re-ordering expenditure was made by excluding personal injury, business claims and other areas from legal aid altogether. These changes have, to date, made only limited in-roads into re-configuring legal aid expenditure towards social welfare law. Moreover, the transfer of personal injury actions to conditional fee arrangements has arguably worsened the position of the financially disadvantaged, and the removal of business claims has taken away important legal support for those catapulted into poverty as a result of the loss of a small business. In harness with re-ordering priorities, the Legal Aid Board put considerable energy into setting up community legal service partnerships to set local and regional priorities.

The partnerships were designed to bring together funders and providers of legal services, to audit existing services, and then highlight gaps and overlaps in provision and services.

Starting with a pilot of six partnerships in 1999, there are now around 200 partnerships operating across England and Wales.

5 Richard Moorhead et al, Quality and costs: final research report on the contracting of non-family, civil advice and assistance pilot. (Institute of Advanced Legal Studies, 2001). 
The success of such partnerships is mixed. Specific initiatives can be pinpointed as arising from the partnerships (for example, the recent opening of the Devon Law Centre in Plymouth and a number of information and communication technology projects to deliver advice) and there are encouraging signs that the Legal Services Commission is piloting new ways of delivering services. ${ }^{6}$ At the same time, expectations of a more coherent joined-up approach to legal services have remained largely unfulfilled. Moreover, the hope that the planning process would give a fillip to funding from other sources towards comprehensive legal services with national coverage has not been realised.

Exerting financial control, giving quality a central place in delivery of legal aid, and introducing a greater measure of coherence have all been achieved as a result of legal aid reform. Nonetheless, substantial gaps in legal services remain, particularly in tribunal representation, whilst changes in delivery have not been matched with improvements to the legal aid means-test. The failure to tackle these issues means that the vision of more effective targeting of legal services towards the poor has seen only modest gains. What lessons does this experience bring to bear on the voluntary sector and professions as we embark on legal aid reform in Northern Ireland?

\section{Legal Aid Reform in Northern Ireland}

The draft Access to Justice (NI) Order 2002 sets out a framework for change, leaving much of the fine detail to be sketched in by regulations, directions, powers and guidance vested in the Lord Chancellor and the new Legal Services Commission. The legislative canvas is broad, leaving the Lord Chancellor, in particular, and the Legal Services Commission, flexibility and considerable scope in deciding what steps are to be taken towards delivering the community legal service and controlling the civil legal aid budget. This approach mirrors that taken by the Access to Justice Act 1999, which paved the way for reform in England and Wales.

This flexibility is likely to prove a mirage. In effect, many of the proposed changes have already been tried and tested in England and Wales. The argument from both branches of the legal profession that Northern Ireland's jurisdiction is unique, calling for local solutions to local problems, has cut no ice with the Lord Chancellor. As a result, delivery of the community legal service largely through contracts, the introduction of conditional fee arrangements and a criminal defence service are all likely to happen in the short or medium term. The Funding Code, quality service measures and arrangements for dealing with exceptionally expensive cases are all likely to borrow heavily from existing approaches in place for England and Wales. In addition, some of the powers contained in the draft Order, of particular concern to the profession, are being held in reserve if initial cost control mechanisms prove ineffective. There will be scope for some divergence, but this is likely to be at the margins.

6 The Community Legal Service has just issued The Partnership Innovation Budget: Proposals for the Second Round of Grants. A central part of the document is to encourage community legal education and develop links between legal advice providers and community groups. 
Moreover, the Legal Services Commission's first task will be to improve turnaround times for processing applications and payments, ending backlogs and delivering a service commensurate with that delivered in England, Wales and Scotland. Tackling this formidable challenge, combined with the limited groundwork done in advance of the commencement of the Legal Services Commission, increases the prospect of the new Commission looking for ideas utilised elsewhere in developing much of its initial thinking. By illustration, it would have been helpful to have undertaken initial work on quality standards by activating the working party on the issue promised in the Decisions Paper The Way Ahead in September 2000. Further, developing a research programme, within or accessible to, the current legal aid department could have produced significant material of value to the new Commission. The Lord Chancellor's Department has a research capacity of its own which has been particularly productive over the past few years. The counter to this criticism is that the new Commission should be given a clean slate to develop its own ideas. The problem, however, for the Commission, is that it will inherit a full agenda from a standing start. A body of existing work focusing on Northern Ireland for the new Commission to draw on would have been a decided advantage.

Nonetheless, there is a lot to be welcomed in the changes being brought forward. First, is the fact that legal services and legal aid are now generating a debate. For too long, legal aid has been a cloistered discussion between a small number of players within government and the profession. This debate will hopefully widen the range of those involved in discussions to encompass the voluntary sector, trade unions, political parties, consumer bodies and, most important of all, those who actually receive legal aid services. A shift of emphasis on to consumers can only be a good thing, reminding all of us about the purpose of legal aid and why it was initially introduced.

For consumers using the community legal service, there will be issues of retaining reasonable choice and access to a legal adviser. Exercising such choice will require consumers to possess a level of information that currently does not exist about who specialises in specific services. At present, the useful legal aid list of solicitors and their specialisms has not been updated for six years.

A debate on providing legal services to the poor through legal aid does not exclude issues of particular interest to providers. It is difficult to look beyond a mixed economy of providers from the private and voluntary sector in the long term. However, the current configuration of private solicitor firms is likely to change over time, with fewer sole practitioner and small practices, particularly if contracts and exacting quality standards are introduced. The ramifications of such a change and its impact on consumer choice and access to services constitute an important debate for the Law Society in particular as well as for other interested groups.

The debate on legal aid may also create space to examine other critical issues. Alternatives to existing delivery of services should be opened up in due course, particularly alternative dispute resolution, public interest litigation and the use of new technology to provide services. The latter carries a small warning inasmuch as technological innovations, while improving access to legal information, bring along with them the danger of widening social exclusion for those without access to computers or who 
suffer language, or literacy problems. A focus on consumers will hopefully lead into the discussion of the role legal services can play in tackling social exclusion and disadvantage.

An additional advantage to legal aid reform will be the creation of the Legal Services Commission itself. An independent body delivering legal aid will enable both parts of the profession to engage in a more robust public debate should service delivery fall short of expectations. Further, the make up of the new Commission will hopefully contain skills and experience gained from a diverse range of backgrounds, including the consumer perspective.

Placing quality standards at the forefront of delivery of service is welcome. Currently, there is no way of knowing whether the quality of advice given, for example, under the green form scheme is consistently good, bad or indifferent. Individual firms may have their own in-house quality controls and use of externally verifiable quality schemes is growing. The Home Charter Scheme run by the Law Society and the Children's Order panel are other examples of quality standards being promoted. The overall picture, however, is one of piecemeal and ad-hoc developments falling short of comprehensive coverage.

For the voluntary sector, quality standards and external performance indicators are a familiar concept. They come hand in hand with service delivery agreements currently negotiated with government departments and other funders. External evaluation is also a regular feature of life in the voluntary sector. For example, in the past six years the Law Centre has had a full organisational review by Price Waterhouse Coopers and reviews of two projects by external organisations to determine whether funding for pilot projects should be mainstreamed. Local Citizen Advice Bureaux work within a quality standards framework and casework recording systems that operate on a United Kingdom wide basis. The Association of Independent Advice Centres has also channelled considerable energies into developing quality standards and accrediting the work of advisers. This does not mean that all quality issues have been addressed, rather, that there is a foundation on which approaches to quality can be built. An issue for the voluntary sector will be ensuring that the Commission's own approach complements existing methods already adopted.

The emphasis on planning of legal services within the draft Access to Justice (NI) Order is also encouraging. Funding sources for legal advice in the voluntary sector are diverse. Five government departments, health and social services boards, health and social services trusts, district councils, Community Fund, charitable trusts, Inland Revenue, Home Office and the European Union all fund voluntary sector advice. The legal profession is commercially funded by clients, businesses, insurance companies, and legal aid monies. There is nothing inherently wrong with this mix of finance within both sectors, providing there is a mechanism to allow an overview to ensure coherence and identify gaps and unnecessary overlaps in services.

Within government in Northern Ireland no department takes a lead responsibility towards ensuring such coherence within the voluntary sector advice services, although there are signs of change. For example, the Department of Enterprise, Trade and Industry has recently released its draft consumer strategy document outlining its desire for a more joined-up 
approach within government to debt and consumer advice. ${ }^{7}$ The Department for Social Development, responsible for the voluntary sector, social security, urban regeneration and housing, is committed to reviewing its advice and information strategy albeit confined solely to its own responsibilities.

Moreover, at present, delivery of legal services by the voluntary sector and legal profession has remained largely separate. There is often good local liaison, but little formal contact. Historically, services delivered between the two sectors have entailed limited overlap. This is beginning to break down. In Belfast and Derry, solicitor firms are beginning to employ para-legal staff to undertake social security, debt and other social welfare legal advice. This change is likely to be accelerated by legal aid reform though it is harder to envisage the voluntary sector moving into areas of advice and litigation more traditionally associated with private practice.

Developing an overview of current provision is likely to push the Legal Services Commission to once again look across the Irish Sea to the work of Community Legal Service Partnerships in England and Wales. Without some mechanism or research into planning, the move towards drawing in the voluntary sector is likely to lead to additional funding without heralding a more visionary approach.

Gaps in legal service provision can already be identified. Mental health is an obvious area where few solicitors or barristers have developed expertise and where people with mental health problems and their carers are not properly served by existing services. Environmental law, a rapidly evolving area, is also likely to benefit from any audit identifying gaps in specialist provision. Further, such an exercise can begin to look at alternative ways of delivering services including Alternative Dispute Resolution. ${ }^{8}$ More problematic will be the approach to dealing with overlap in provision. In practice, what may happen is that changes introduced elsewhere through the Funding Code, quality standards initiatives and registration requirements for legal aid providers may ameliorate the extent of this dilemma.

One lesson emerging from an analysis of legal aid reform is the need for more formal liaison between the legal profession and the voluntary sector. The Law Society and Bar Council have resources and an entrée to government and other key opinion formers that the voluntary sector can only envy. At the same time, any public foray by the legal profession into the debate on legal aid is hamstrung by the public perception that the profession is looking after its own interests and not those of consumers. In contrast, the voluntary sector is not handicapped by any such ambivalence. The question arises as to whether there are common interests to sustain such an alliance. In broad terms, on questions of level of funding for legal aid, a more generous means-test, and an antipathy towards conditional fee arrangements for personal injury actions, there is clearly considerable scope for cooperation.

7 A draft consumer strategy consultation by the Minister for Enterprise, Trade and Investment, issued March 2002

8 Alternative Dispute Resolution may become even more important following the Court of Appeal decision in England, Cowl and others v Plymouth City Council, The Times 8 January 2002). The judgment placed particular emphasis on the need to engage in ADR and avoid court action whenever possible. 
This positive assessment of change could, however, be undermined unless other aspects of legal aid and civil justice are properly addressed. Financial eligibility for legal aid has tightened in real terms. The proportion of people entitled to civil legal aid has declined over the past twenty years. In England and Wales, the proportion of the population potentially entitled to civil legal aid has dropped from the high watermark of $78 \%$ in 1979 to less than $50 \%$ by the mid 1990s. Since then this decline has continued inexorably. No equivalent figures appear to have been published for Northern Ireland, nonetheless, it is now clear that full entitlement to civil legal aid is effectively a mark of poverty. People in work and on low incomes and older people with modest savings and small occupational pensions can now find themselves faced with a prohibitive legal aid contribution which places legal services out of reach (see Box 1 for a recent Law Centre case that graphically illustrates the problem).

In addition, outside of those on specific benefits passported to free green form legal advice and assistance, few others can qualify on financial grounds.

\section{Box 1: Civil legal aid assessment May 2002}

Mr and Mrs A are aged 82 and 67 and applied for civil legal aid. $\mathrm{Mr}$ and Mrs A have savings of $£ 5866$. The couple have a total income of $£ 137.43$ a week consisting of Mrs A’s pension of $£ 88.39$, Mrs A's pension of $£ 30.58$ and Mr A's occupational pension of $£ 18.46$.

Total income is $£ 18.33$ a week above the minimum income guarantee (recognised level of entitlement to income support).

Mr and Mrs A were required to pay a contribution of $£ 3741$ by way of an initial instalment of $£ 2940$ followed by 11 monthly instalments of $£ 72.75$.

A review of financial eligibility for legal aid is overdue. A radical new approach is needed to expand the number of people who are entitled to publicly funded legal services. Government has taken a number of initiatives to boost the financial circumstances of low income families, including the introduction of tax credits. Paradoxically, this has led to less access to legally aided publicly funded services. In addition, recognition of the impact of modest savings and occupational pensions on entitlement to means-tested benefits is being recognised and addressed by government. No such parallel initiative is in place to preserve entitlement to legal aid. The predicament for legal aid reform is that services targeted on social welfare areas of law may miss the mark altogether. It is often the low paid or those in other circumstances just above benefit level who are seriously at risk of debt, housing re-possession, employment problems etcetera. 
A close relation of financial eligibility is the question of funding for legal aid as a whole. A legitimate concern with those providing legal services is that reform will herald cost reductions as well as cost controls of legally aided services. If new and imaginative approaches to delivering legal services are to be championed, gaps in services to be effectively filled and in-roads to be made in targeting social welfare law, sufficient funding must be provided.

Bearing in mind the priority given to health and education in public spending rounds, making the case for properly funded legal aid services will not be easy. A task for all those involved and interested in legal services including the new Legal Services Commission will be to sell the virtues of access to justice.

A further dimension to the legal services debate will be the approach of the Lord Chancellor's Department to tribunal representation following the publication of the Leggatt review. ${ }^{9}$ A response is expected during this summer. The review recommended that its proposal should be fully examined in Northern Ireland. To date, a watching brief has been maintained by government departments with no pro-active public debate being initiated. The Leggatt proposals favoured an overarching, more coordinated approach to administration of tribunals vested in the Lord Chancellor's Department, which would have responsibility for implementing information technology and other reforms comprehensively across all tribunals. What Leggatt did not fully answer was the dilemma that almost all tribunals require third party assistance (lay or legal representation depending on the circumstances) due to the complexity and importance of the issues involved. If legal aid is to be a piece in the jigsaw which provides effective legal services to the financially disadvantaged then, imaginative solutions to the need for representation at tribunals or reform of the current tribunals system will need to be crafted.

A final area for scrutiny is support for people taking or defending claims at the small claims court. The increase in the financial limit to $£ 2,000$ following the civil justice review still leaves the limit substantially below the $£ 5,000$, for example, limit operating in England and Wales. A financial claim of $£ 1500$ is extremely significant for a person on low income. Any attempt to move the limit upwards without addressing access to advice, assistance and in some cases representation, will create a vacuum in access to justice. Research into the impact of the change in the financial limit on settlements and applicants' perception of the small claims court would be an extremely useful starting point. The Legal Services Commission will need to look at innovative and cost effective ways of funding legal support in the small claims court. This is an area in which the voluntary sector may have a particular role to play.

\section{CONCLUSION}

Legal aid reform presents opportunities and challenges for the voluntary sector and legal profession. Shaping as well as responding to change will be a challenge to both sectors. For the voluntary sector, legal aid reform

9 Tribunals for Users (the "Leggatt” Report, 2001). 
178 Northern Ireland Legal Quarterly [Vol. 53, No. 2]

represents a concrete recognition that advice agencies are part of legal services with a legitimate voice in the debate on improving access to justice. Ensuring this debate leads to the best possible legal services for financially disadvantaged consumers is the prize still to be won. 